\title{
Effects of Social Interaction and Warm Ambient Temperature on Brain Hyperthermia Induced by the Designer Drugs Methylone and MDPV
}

\author{
Eugene A Kiyatkin*,', Albert H Kim', Ken T Wakabayashi', Michael H Baumann' and Yavin Shaham' \\ 'Intramural Research Program, NIDA-NIH, Baltimore, MD, USA
}

\begin{abstract}
3,4-Methylenedioxymethcathinone (methylone) and 3,4-methylenedioxypyrovalerone (MDPV) are new drugs of abuse that have gained worldwide popularity. These drugs are structurally similar to 3,4-methylenedioxymethamphetamine (MDMA) and share many of its physiological and behavioral effects in humans, including the development of hyperthermia during acute intoxication. Here, we examined the effects of methylone ( $1-9 \mathrm{mg} / \mathrm{kg}$, s.c.) or MDPV $(0.1-1.0 \mathrm{mg} / \mathrm{kg}$, s.c.) on brain temperature homeostasis in rats maintained in a standard laboratory environment (single-housed in a quiet rest at $22^{\circ} \mathrm{C}$ ) and under conditions that model human drug use (social interaction and $29^{\circ} \mathrm{C}$ ambient temperature). By simultaneously monitoring temperatures in the nucleus accumbens, temporal muscle, and facial skin, we assessed the effects of methylone and MDPV on intra-brain heat production and cutaneous vascular tone, two critical factors that control brain temperature responses. Both methylone and MDPV dose-dependently increased brain temperature, but even at high doses that induced robust locomotor activation, hyperthermia was modest in magnitude (up to $\sim 2^{\circ} \mathrm{C}$ ). Both drugs also induced dose-dependent peripheral vasoconstriction, which appears to be a primary mechanism determining the brain hyperthermic responses. In contrast to the powerful potentiation of MDMA-induced hyperthermia by social interaction and warm ambient temperature, such potentiation was absent for methylone and minimal for MDPV. Taken together, despite structural similarities to MDMA, exposure to methylone or MDPV under conditions commonly associated with human drug use does not lead to profound elevations in brain temperature and sustained vasoconstriction, two critical factors associated with MDMA toxicity.

Neuropsychopharmacology (2015) 40, 436-445; doi:1 0.1038/npp.2014.191; published online 27 August 2014
\end{abstract}

\section{INTRODUCTION}

Recently, there has been a rapid increase in the abuse of synthetic cathinone analogs that are sold with innocuous names such as 'bath salts' or 'plant food' (Baumann et al, 2013a; German et al, 2014). Such products are designed to circumvent the regulations controlling the sale and use of psychoactive substances. Two very popular synthetic cathinones are 3,4-methylenedioxymethcathinone (methylone) and 3,4-methylenedioxypyrovalerone (MDPV) (Spiller et al, 2011). Although low recreational doses of synthetic cathinones enhance mood and increase energy, high doses or chronic use can cause serious medical complications, including agitation, psychosis, tachycardia, hyperthermia, and even death (Prosser and Nelson, 2012; Ross et al, 2012). Because of these risks, methylone and MDPV have been classified as Schedule I controlled substances in the United States (DEA, 2011).

Methylone and MDPV display structural similarities to the illicit drug 3,4-methylenedioxymethamphetamine

*Correspondence: Dr EA Kiyatkin, Behavioral Neuroscience, NIDAIRP, 333 Cassell Drive, Baltimore, MD 21224, USA, Tel: +443740 2844, Fax: +443 740 2155, E-mail: ekiyatki@intra.nida.nih.gov

Received 4 June 20।4; revised 24 July 20I4; accepted 25 July 20।4; accepted article preview online 30 July 2014
(MDMA, 'Ecstasy'). Like MDMA, methylone and MDPV exert their effects by interacting with monoamine transporter proteins in the central and peripheral nervous systems (Baumann et al, 2013a). Methylone is a non-selective transporter substrate that evokes the release of dopamine, norepinephrine, and serotonin, analogous to the effects of MDMA (Baumann et al, 2012; Eshleman et al, 2013; Simmler et al, 2013). By contrast, MDPV is a potent transporter blocker that inhibits the uptake of dopamine and norepinephrine, with minimal effects on serotonin uptake (Baumann et al, 2013b; Cameron et al, 2013). Both drugs increase extracellular dopamine in the nucleus accumbens (NAc) of rats (Baumann et al, 2012, 2013b) and are readily self-administered (Aarde et al, 2013; Watterson et al, 2014), suggesting that their chronic use can lead to addiction.

One of the most dangerous side effects of stimulant drugs of abuse is elevated brain and body temperature (Kiyatkin, 2013). In humans, robust increases in body temperature have been reported during acute intoxication with both methylone (Pearson et al, 2012) and MDPV (Borek and Holstege, 2012; Murray et al, 2012; Kesha et al, 2013). Despite such clinical evidence, the reported temperature effects of methylone and MDPV in laboratory animals are controversial, varying according to species, age, dose, and 
experimental conditions (Baumann et al, 2012; Aarde et al, 2013; Fantegrossi et al, 2013; Merluzzi et al, 2013). Repeated methylone (3-10 mg/kg, subcutaneously (s.c.)) injections increase core temperature in rats (Baumann et al, 2012), but such elevations are less than those induced by MDMA. MDPV is reported to cause hyperthermia in mice (3-30 mg/kg, i.p.) but only at elevated ambient temperature (Fantegrossi et al, 2013). In rats, acute MDPV (1.0-5.6 mg/kg, s.c.) has no effect on core temperature (Aarde et al, 2013). Thus, it remains unclear whether methylone and MDPV affect temperature homeostasis in rodents, and how the effects of these drugs are modulated under conditions that mimic human drug use. The latter issue is important because methylone and MDPV may be abused at 'rave parties', social gatherings where participants experience high levels of physiological activation in warm humid environments that prevent proper heat dissipation.

We have previously shown that hyperthermic responses to MDMA (Brown and Kiyatkin, 2004; Kiyatkin et al, 2014) are greatly enhanced when these drugs are administered to rats during social interaction and in moderately warm environments, two conditions that model human drug use. However, it is unknown whether methylone and MDPV also potentiate hyperthermic responses under these conditions. Here, we examined the effects of these drugs on brain, muscle, and skin temperatures in freely moving rats. We first examined the effects of the drugs on these temperature measures in quiet resting conditions at standard ambient temperatures $\left(22^{\circ} \mathrm{C}\right)$. We then examined the effect of methylone and MDPV on these measures during social interaction (exposure to a conspecific male) and at increased ambient temperatures $\left(29^{\circ} \mathrm{C}\right)$.

To assess brain temperature, we chose the NAc, a deep brain structure involved in sensorimotor integration and psychostimulant reward (Mogenson et al, 1980; Wise, 1989; Badiani et al, 2011). Although brain temperature was the primary parameter in this study, we also measured temperatures in temporal muscle and facial skin. This three-point recording procedure allowed us to assess how drugs affect intra-brain heat production and skin vascular tone (vasoconstriction/vasodilation), two factors determining brain and body hyperthermia (Kiyatkin, 2010; Kiyatkin et al, 2014).

\section{MATERIALS AND METHODS}

\section{Subjects, Surgery, and Thermocouple Sensors}

We used 18 Long-Evans rats (Charles River Laboratories, 3-4-months old, $450 \pm 30 \mathrm{~g})$ that were housed individually (12-h light cycle beginning at 07:00) with free access to food and water. All experiments complied with the 'Guide for the care and use of laboratory animals' ( $8^{\text {th }}$ edition); protocols were approved by the Animal Care and Use Committee. Each rat underwent the same procedure of three-point thermocouple electrode implantation described in detail elsewhere (Kiyatkin and Brown, 2004). Briefly, under general anesthesia, we chronically implanted miniature copper-constantan thermocouple probes $(125 \mu \mathrm{m}$ in diameter) in the NAc shell, temporal muscle, and subcutaneously, along the nasal ridge with the tip approximately $15 \mathrm{~mm}$ anterior to bregma. We secured the probes with dental cement to three stainless steel screws threaded into the skull. We began the experiments 5 days after surgery.

Because the temporal muscle and the brain receive a common blood supply from the carotid artery, and thus are equally exposed to blood-delivered heat influences from the body, NAc-Muscle temperature differentials show the source of heat production, providing a measure of druginduced metabolic brain activation (Kiyatkin, 2010). Skin temperature is determined primarily by the state of peripheral vessels, but it also depends on the temperature of arterial blood inflow. Therefore, changes in Skin-Muscle temperature differentials reveal drug action on cutaneous vascular tone, another important determinant of brain temperature changes (Kiyatkin, 2010).

\section{Experimental Procedures}

The experimental procedures were identical to those we described in our recent paper (Kiyatkin et al, 2014). All recordings took place during the light phase in a light- and sound-attenuating chamber. Each morning, we brought the rats from their housing facility, placed them in the chamber, and connected them to the recording instrument (Thermes-16, Physitemp Instruments). We habituated rats to the recording environment for two sessions before and one session after the surgery ( $6 \mathrm{~h}$ each) and also allowed at least $2 \mathrm{~h}$ of habituation during each drug session. We recorded temperatures continuously with 10 -s time bins and maintained room temperature at either $22.5 \pm 0.5{ }^{\circ} \mathrm{C}$ ('standard laboratory conditions') or $29.0 \pm 0.5^{\circ} \mathrm{C}$ ('warm environmental conditions'). In all experiments, we also measured locomotor activity using photobeams as previously described (Kiyatkin and Brown, 2004).

We exposed all rats to the same 2-week experimental protocol. During the first week, we examined temperature and locomotor responses produced by either methylone $(1,3$, and $9 \mathrm{mg} / \mathrm{kg} ; 10$ rats) or $\operatorname{MDPV}(0.1,0.3$, and $1.0 \mathrm{mg} / \mathrm{kg}$; 8 rats) under quiet resting conditions at standard ambient temperatures $\left(22-23^{\circ} \mathrm{C}\right)$. We injected each drug s.c. in $0.3 \mathrm{ml}$ saline during three consecutive sessions, in which we employed an ascending dose-response regimen (low, medium, and high doses on sessions 2, 3, and 4, respectively). Because our injection procedure induces some stress, we examined the effects of s.c. saline injections $(0.3 \mathrm{ml})$ in two sessions (1 and 5), one preceding and one following the drug sessions. We gave all injections when rats were in quiet resting, sleep-like conditions when all temperatures had stabilized at low basal levels. We chose the drug doses based on their known affinity to monoamine transporters and their ability to stimulate locomotion (Baumann et al, 2013b).

During the second week of testing, we exposed rats to four experimental sessions. During the first two sessions, we tested the effects of s.c. saline and methylone or MDPV (9 or $1 \mathrm{mg} / \mathrm{kg}$, respectively) during social interaction. We placed a novel, drug-naive conspecific male in the experimental rat's cage $10 \mathrm{~min}$ before and removed the intruder rat $50 \mathrm{~min}$ after the drug/saline injection. During this time period, the two rats freely interacted with each other. We refer to this experimental manipulation as 'social interaction', because both rats typically show increased locomotion, sniffing, rearing, and oro-genital contact but no signs of overt 
aggressive or defensive behavior. During the next two sessions, we examined the effects of saline and methylone or MDPV (9 or $1 \mathrm{mg} / \mathrm{kg}$, respectively) at $29^{\circ} \mathrm{C}$ ambient temperatures. Although this temperature is $6-7^{\circ} \mathrm{C}$ higher than standard housing conditions $\left(22-23^{\circ} \mathrm{C}\right)$, it corresponds to the thermoneutral zone in rats, where endogenous heat production is minimal and balanced with heat loss (Romanovsky et al, 2002). In all experiments, we recorded temperature and locomotion for at least $5 \mathrm{~h}$ after drug or saline injections. To exclude the possible experiencedependent changes in temperature responses, we counterbalanced the order of the saline and drugs injections as well as the two experimental conditions.

\section{Data Analysis}

We analyzed temperature changes four ways: as absolute changes in each recording location, as relative changes, as NAc-Muscle and Skin-Muscle temperature differentials (a difference between relative temperature changes in the corresponding locations), and as a difference from the saline control condition. The latter parameter (drug-saline) allowed us to exclude the influence of the injection procedure from the total temperature response and reveal 'net' drug effects. We analyzed the patterns of temperature and locomotor effects over time for each drug dose and each condition, using one-way repeated measures ANOVA; we followed up on significant ANOVA results with Fisher's PLSD post hoc tests. Because of space limitations, we provide a detailed reporting of the $\mathrm{F}$ values for individual time-course analyses in Supplementary Table 1. Because the duration of temperature and locomotor responses differed for each drug, each dose, and each condition, we analyzed between-group comparisons in temperature parameters and locomotion by calculating the mean area under the curve (sum of 3 -min values for the entire 5-h post-injection interval). We assessed between-group differences by using one-way ANOVA with subsequent Fisher's PLSD post hoc tests. We report the results of between-dose and betweengroup comparisons in the figure legends.

\section{RESULTS}

\section{Effects of Methylone and MDPV on Temperature Homeostasis During Quiet Resting Conditions at Standard Ambient Temperature}

Methylone. As shown in Figure 1 (top row), injections of methylone and saline had significant but different effects on temperatures. Although saline induced a transient increase in NAc and muscle temperatures, a short-term fall in skin temperature, and weak increase in locomotion (Figure 1a and $d$ ), these changes were stronger and more prolonged after methylone injections at each dose (Figure 1e-g). After we excluded the non-specific influences of the injection procedure (saline condition) from these responses, we found that methylone alone dose-dependently increased NAc and muscle temperatures. At $1 \mathrm{mg} / \mathrm{kg}$, temperatures increased $\sim 1{ }^{\circ} \mathrm{C}$ for $\sim 60 \mathrm{~min}$ post injection (Figure $1 \mathrm{~h}$ ), and the response was doubled in magnitude $\left(\sim 2^{\circ} \mathrm{C}\right)$ and continued for $\sim 4.5 \mathrm{~h}$ at the $9 \mathrm{mg} / \mathrm{kg}$ dose (Figure $1 \mathrm{n}$ ). Methylone had no effect on NAc-Muscle differentials, suggesting a lack of effect on intra-cerebral heat production, but dose-dependently decreased Skin-Muscle differentials, suggesting cutaneous vasoconstriction (Figure 1i, e, o, r). Methylone dose-dependently increased locomotion but motor activation was clearly evident only at $9 \mathrm{mg} / \mathrm{kg}$ (Figure 1j, m, p, s).

$M D P V$. This drug induced its greatest changes immediately after the injections, with clear differences $v s$ saline at 0.3 and $1.0 \mathrm{mg} / \mathrm{kg}$ (Figure 2a and $\mathrm{e}-\mathrm{g}$ ). When the non-specific influence of the saline injection was excluded, we found that MDPV at the lowest dose $(0.1 \mathrm{mg} / \mathrm{kg})$ had a biphasic effect on brain and muscle temperatures. Both parameters slightly increased after the injection $\left(\sim 0.2^{\circ} \mathrm{C}\right)$ but then clearly decreased $\left(\sim 0.7^{\circ} \mathrm{C}\right)$ below the baseline from $\sim 150 \mathrm{~min}$ post injection. At this low dose, MDPV had minimal effects on locomotion (Figure $2 \mathrm{j}$ ). At a moderate dose $(0.3 \mathrm{mg} / \mathrm{kg})$, MDPV induced a clear hyperthermic effect in the NAc and muscle (Figure 2k) as well as robust hyperlocomotion (Figure $2 \mathrm{~m}$ ); both of these effects were clearly enhanced at the $9 \mathrm{mg} / \mathrm{kg}$ dose (Figure $2 \mathrm{n}$ and $\mathrm{p}$ ). At each dose, MDPV also increased NAc-Muscle differentials; however, this effect was weak, evident only within 10-30 min post injection, and similar at each drug dose (Figure 2i, l, o, r). In contrast, Skin-Muscle differentials decreased by MDPV in a dose-dependent manner (Figure 2i, 1, o, r).

\section{Effects of Methylone and MDPV During Social Interaction}

Consistent with previous studies (Brown and Kiyatkin, 2004; Kiyatkin et al, 2014), social interaction between two rats resulted in robust increases in NAc and muscle temperatures, rapid biphasic (down-up) changes in skin temperature, and strong locomotor activation (Figure 3a-c). These changes were tightly related to the duration of social interaction and the mean NAc temperature increase $\left(\sim 2.2^{\circ} \mathrm{C}\right)$ exceeded those induced by either methylone or MDPV alone at the highest doses $\left(\sim 1.8^{\circ} \mathrm{C}\right)$ under quiet resting conditions. Social interaction also significantly increased NAc-Muscle differential and rapidly decreased Skin-Muscle differential, which returned to baselines $\sim 30$ $40 \mathrm{~min}$ after the end of social interaction (Figure $3 \mathrm{~b}$ ).

Methylone. When we injected rats with methylone $(9 \mathrm{mg} / \mathrm{kg})$ $10 \mathrm{~min}$ after the start of social interaction, the resulting changes were minimal, manifesting as a more delayed decrease of all temperatures and locomotion, and a more prolonged decrease in the Skin-Muscle differential (Figure 3d-f). Although mean changes in all parameters in this group were larger than in rats injected with saline, the differences were minimal and statistically not significant (Figure $3 \mathrm{j}-1$ ). When the changes in control (social interaction + saline) were subtracted from those seen with the drug (social interaction + methylone), we found that methylone during social interaction induced a biphasic change in NAc and muscle temperatures, slightly decreasing both parameters after the injection and inducing more delayed and weaker increases thereafter (Figure $4 \mathrm{~d}$ ). Compared with quiet resting conditions, the NAc temperature increase induced by methylone during social interaction was weaker in terms of both the magnitude $(1.40 \pm 0.22 \mathrm{vs}$ 

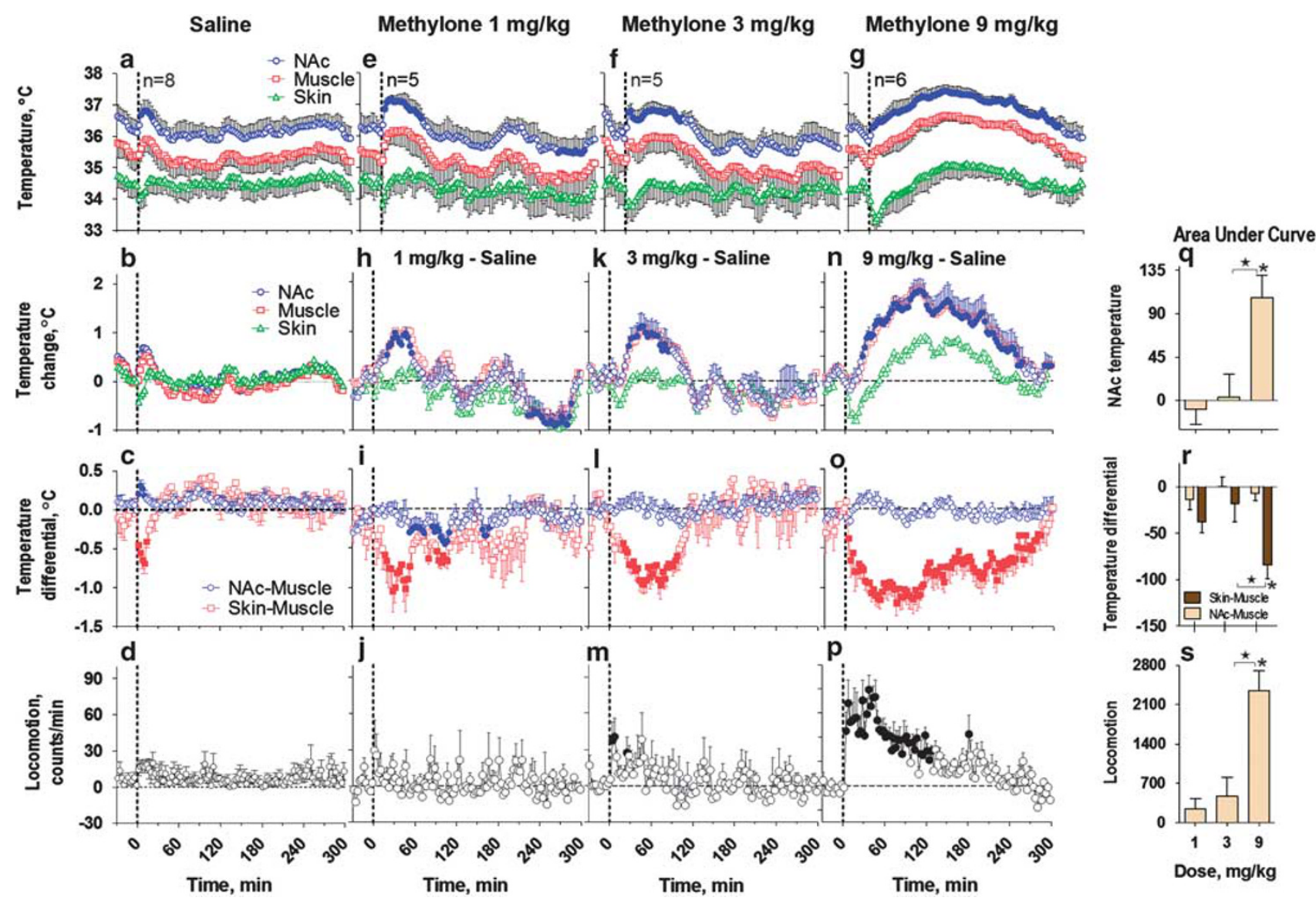

Figure I Temperature and locomotor effects of methylone in rats under quiet resting conditions at standard ambient temperatures $\left(22-23^{\circ} \mathrm{C}\right)$. Mean \pm SEM changes in NAc, muscle, and skin temperatures after injections of saline $(a-d)$ and methylone (e-g). $n=$ number of averaged responses per group. 'Net' effects of drugs (with effects of saline subtracted) are shown as relative temperature changes ( $h, k, n)$, temperature differentials (i, l, o), and locomotion (j, $m, p)$. All quantitative results of statistical evaluations of time-course analyses (repeated measures one-way ANOVA F-values) for this and subsequent data sets are shown in the Supplementary Table I. Filled symbols show values significantly different from baseline $(P<0.05)$. Right panel $(q-s)$ shows mean \pm SEM values of drug's effects at each dose on individual parameters as assessed by the area under the curve for $5 \mathrm{~h}$ post injection ( $\mathrm{q}-\mathrm{s}$ ). The effect of dose was significant for NAc temperature, Skin-Muscle differential, and locomotion $\left(F_{2.15}=9.3,5.0\right.$ and $\mid 4.5$; $\left.P<0.05\right)$ but not significant for NAcMuscle differential. Asterisks and stars show significant differences between I and $9 \mathrm{mg} / \mathrm{kg}$ and between 3 and $9 \mathrm{mg} / \mathrm{kg}$, respectively $(P<0.05 ;$ Fisher's PLSD test).

$1.83 \pm 0.25^{\circ} \mathrm{C}$ ) and the area under the curve; the latter change did not reach statistical significance (Figure 4j). In both conditions, increases in NAc-Muscle differentials were small but the mean values, assessed by area under the curve, were significantly larger $(P<0.05)$ in the methylone group than in the saline group (Figure $4 \mathrm{k}$ ). In contrast to the rapid and strong decrease in Skin-Muscle differentials induced by methylone under quiet resting conditions (Figure $4 \mathrm{~b}$ ), this effect was delayed and weaker during social interaction (Figure 4e), and the mean area under the curve was significantly lower (Figure $4 \mathrm{k}$ ). Finally, when injected during social interaction, when rats showed high locomotion, the motor-activating effects of methylone were initially fully blocked, being lower than in the control condition after drug injection and slightly increasing thereafter (Figure $4 \mathrm{f}$ and $\mathrm{l}$ ).

$M D P V$. Relatively weak changes in temperature were also observed when MDPV (1 mg/kg) was injected during social interaction (Figure 3g-i). Similar to methylone, these changes manifested as more sustained elevation of all temperatures before returning to baseline levels. However, in this case, mean change in NAc temperature in the MDPV group was significantly larger than in the saline and methylone groups (Figure 3j). Similarly, the changes in NAcMuscle and Skin-Muscle differentials were somewhat higher than those seen in the saline condition, but the effect did not reach statistical significance. In contrast to the saline group (Figure $3 \mathrm{c}$ ), motor activity in the MDPV group continued for more than $2 \mathrm{~h}$ after drug injection (Figure 3i) and its mean value was threefold larger than in the methylone and saline groups (Figure 31). After calculating drug-saline differences (Figure 5), we found that MDPVinduced increases in NAc and muscle temperatures were delayed, peaks were shifted to later times, the response duration became more prolonged, and the total area under the curve increased slightly but significantly $v s$ quiet resting conditions (Figure $5 \mathrm{~d}$ and $\mathrm{j}$ ). Similar to methylone, there were no between-state differences in changes of NAcMuscle differentials but decreases in Skin-Muscle differentials became smaller in magnitude, more delayed, and weaker as measured by area under the curve (Figure 5e and k). 

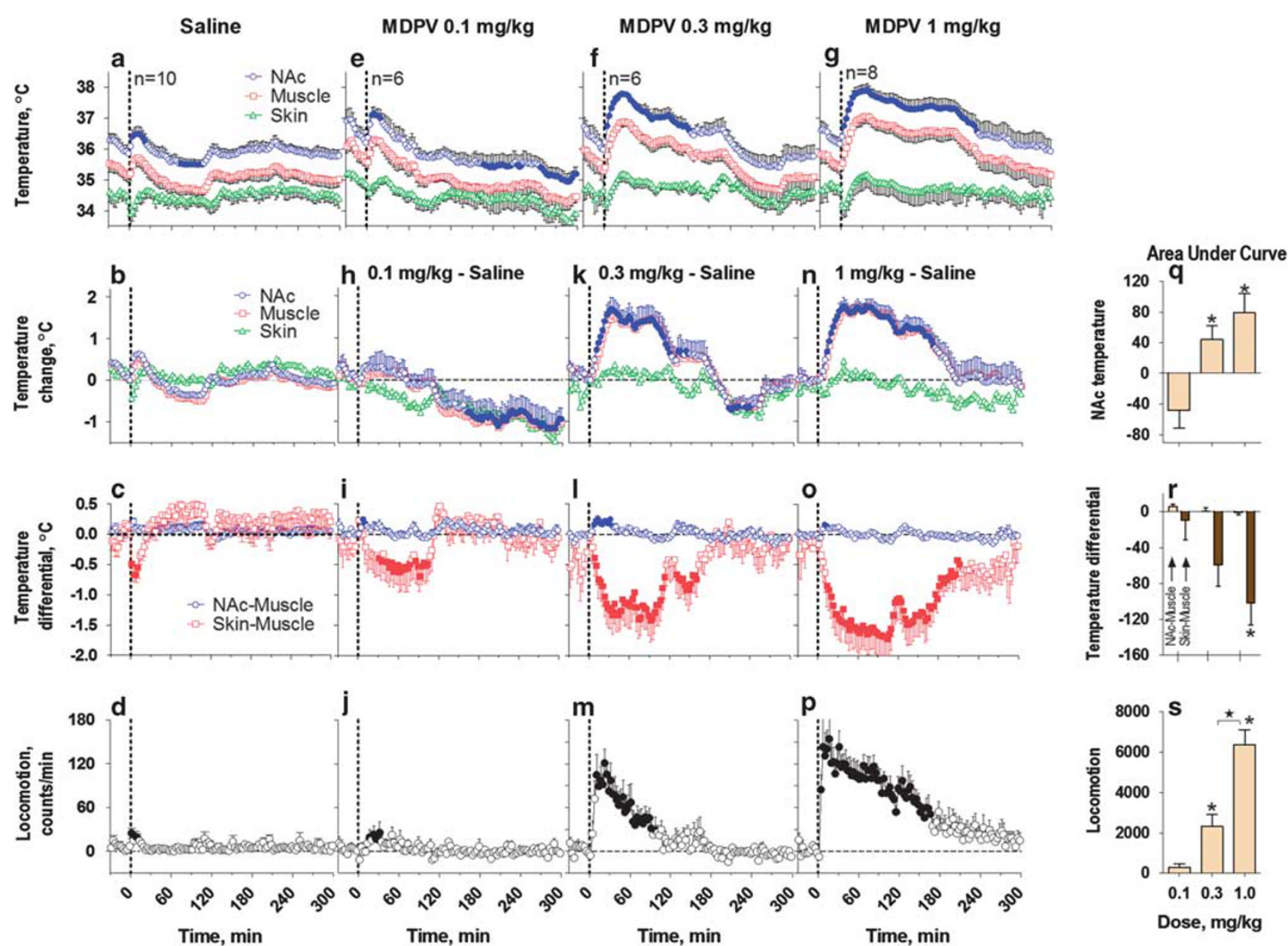

Figure 2 Temperature and locomotor effects of MDPV in rats under quiet resting conditions at standard ambient temperatures $\left(22-23^{\circ} \mathrm{C}\right) . \mathrm{Mean} \pm \mathrm{SEM}$ changes in NAc, muscle, and skin temperatures induced by injections of saline (a-d) and MDPV (e-g). Filled symbols show values significantly different from baseline $(P<0.05) . n=$ number of averaged responses per group. 'Net' effects of drugs (with effects of saline subtracted) shown as relative temperature changes $(h, k, n)$, temperature differentials $(i, l, o)$, and locomotion $(j, m, p)$. Right panel $(q-s)$ shows mean \pm SEM values of drug's effects on individual parameters at different doses as assessed by the area under the curve for $5 \mathrm{~h}$ post injection. The effect of drug dose was significant for NAc temperature, Skin-Muscle differential, and locomotion $\left(F_{2,17}=8.7,4.5\right.$ and 28.8; all $\left.P<0.05\right)$ but not significant for the NAc-Muscle differential. Asterisks show significant differences compared to $0.1 \mathrm{mg} / \mathrm{kg}$ and star shows significant differences between 0.3 and $1.0 \mathrm{mg} / \mathrm{kg}(P<0.05$; Fisher's PLSD test).

However, the latter change did not reach statistical significance. MDPV injected during social interaction continued to equally stimulate locomotion (Figure 51), but the response pattern was changed, with a slower onset and an activation peak moved to the later post-injection time (Figure 5f).

\section{Effects of Methylone and MDPV at Moderately Warm Ambient Temperatures}

The basal temperatures in rats maintained at $29^{\circ} \mathrm{C}$ were slightly higher than those in rats at $23^{\circ} \mathrm{C}$ (Figure 6). The difference was minimal for the NAc $\left(0.42^{\circ} \mathrm{C}\right)$, slightly larger for muscle $\left(0.63{ }^{\circ} \mathrm{C}\right)$, and maximal for the skin $\left(1.06^{\circ} \mathrm{C}\right.$; $P<0.05$ vs $23^{\circ} \mathrm{C}$ ). Saline injections at $29^{\circ} \mathrm{C}$ (Figure 6a-c) induced similar temperature and locomotor changes as were seen at $23{ }^{\circ} \mathrm{C}$ (compare with Figure 1).

Methylone. Similar to control conditions, methylone $\left(9 \mathrm{mg} / \mathrm{kg}\right.$ ) injected at $29^{\circ} \mathrm{C}$ increased NAc (peak at $38.81 \pm$ $0.16^{\circ} \mathrm{C}$ or $+2.27^{\circ} \mathrm{C}$ ) and muscle temperatures, a down-up fluctuation in skin temperature, significant and opposite changes in NAc-Muscle and Skin-Muscle differentials, and locomotor activation (Figure $6 \mathrm{~d}-\mathrm{f}$ ). These changes for all parameters were significantly larger than those induced by saline. When the 'net' effects of methylone were compared for 23 and $29^{\circ} \mathrm{C}$ (Figure $4 \mathrm{~g}-\mathrm{i}$ ), the increase in NAc temperature was more rapid but shorter at $29^{\circ} \mathrm{C}$ than that at $23^{\circ} \mathrm{C}$. Despite a strong decrease in mean area under the curve, this change was not significantly different from that induced by this drug at quiet resting condition (Figure 4j). In contrast to minimal changes in NAc-Muscle differential at $23^{\circ} \mathrm{C}$, this parameter significantly increased after drug injections in warm ambient temperatures, but the decrease in Skin-Muscle differentials became shorter and significantly weaker (Figure $4 \mathrm{~h}$ and $\mathrm{k}$ ). The locomotor response was lower, but the difference compared with control was not significant (Figure 4i-1).

$M D P V$. At $29^{\circ} \mathrm{C}, \mathrm{MDPV}$ induced powerful increases in NAc temperature, strong changes in NAc-Muscle and Skin-Muscle 

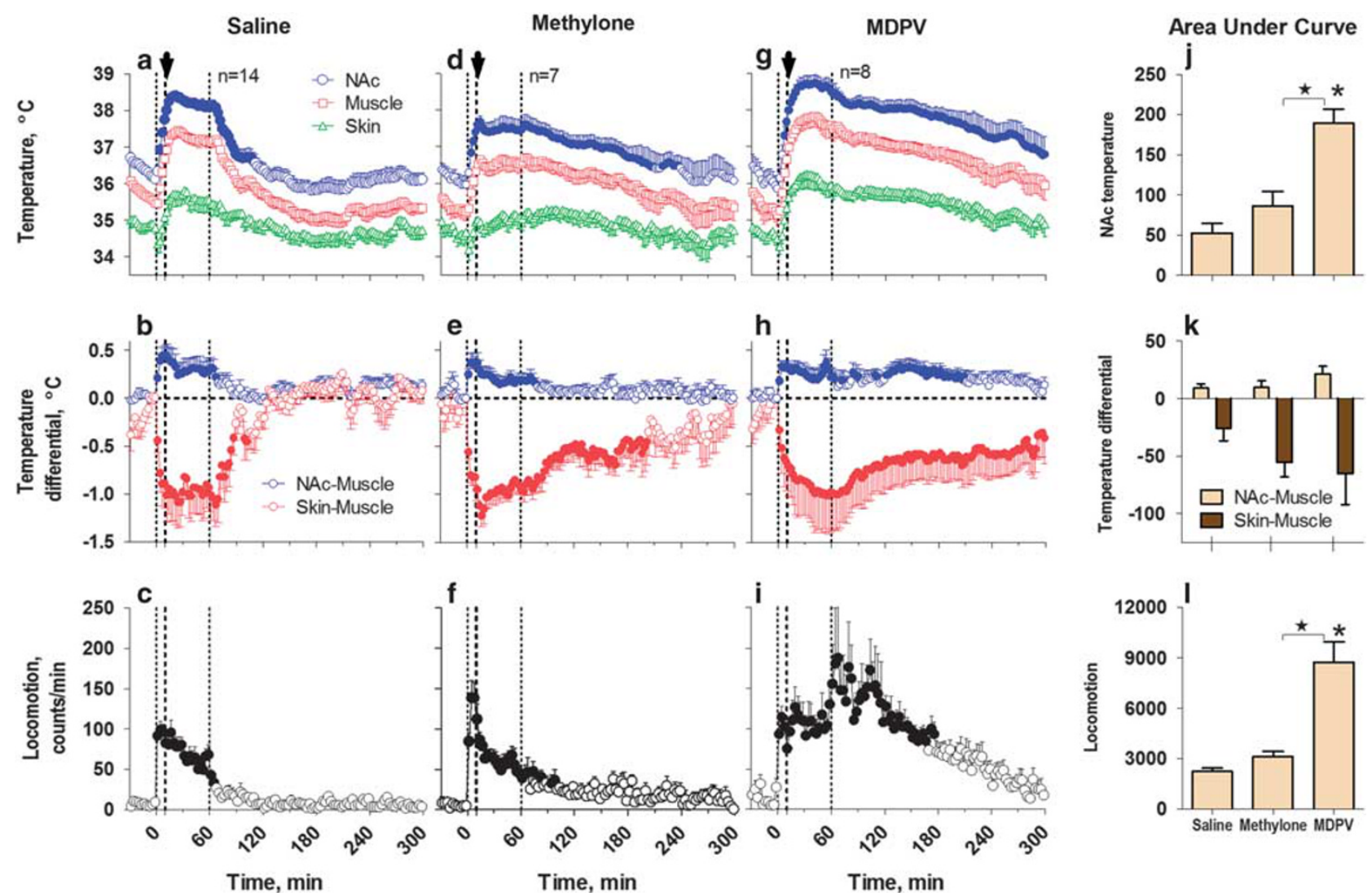

Figure 3 Changes in temperature and locomotion during I-h social interaction (vertical hatched lines at 0 and 60 min) after injections of saline (a-c), methylone $(\mathrm{d}-\mathrm{f})$, and MDPV $(\mathrm{g}-\mathrm{i})$. Top graphs show absolute temperature changes, middle graphs show temperature differentials, and bottom graphs show changes in locomotor activity. $n=$ number of averaged responses per group. Arrows at 10 min shows the time of drug/saline injection. Filled symbols show values significantly different from baseline $(P<0.05)$. Note that the values of locomotor activity during social interaction $(0-60$ min) reflect the sum of two rats. Right panel (j-l) shows mean \pm SEM values of temperature and locomotor responses assessed by the area under the curve for $5 \mathrm{~h}$ post injection. The effect of drug treatment was significant for NAc temperature and locomotion $\left(F_{2,27}=22.2,31.6 ; P<0.05\right)$ but not for NAc-Muscle and Skin-Muscle differentials. Asterisks show significant differences compared to saline, and stars show significant between-drug differences $(P<0.05$; Fisher's PLSD test).

differentials and a robust locomotor activation (Figure $6 \mathrm{~g}-\mathrm{i}$ ). These changes were uniformly greater than those induced by saline or methylone (Figure 6j). In this case, the response pattern remained the same, but NAc and muscle temperature increases were stronger and more prolonged than those at $23^{\circ} \mathrm{C}$ (Figure 5). At $29^{\circ} \mathrm{C}$, MDPV increased NAc temperatures more slowly, to a higher peak, and for a longer time than at $23^{\circ} \mathrm{C}$ (Figure $5 \mathrm{~g}$ ), resulting in a significant increase in the area under the curve (Figure 5j). Similar to methylone, MDPV at $29^{\circ} \mathrm{C}$ increased NAc-Muscle differentials $(P<0.05)$ but the decrease in Skin-Muscle differentials did not differ significantly from the control (Figure $5 \mathrm{~b}, \mathrm{~h}$ and $\mathrm{k}$ ). MDPV injections at $29^{\circ} \mathrm{C}$ also induced slightly weaker but more prolonged locomotor activation, but the mean change evaluated as an area under the curve did not differ (Figure 5c, $\mathrm{i}$ and 1$)$.

\section{DISCUSSION}

Methylone and MDPV are structurally similar to MDMA, interact with the same monoamine transporter proteins, and share a number of behavioral and physiological effects (Baumann et al, 2013a; German et al, 2014). Recently, we reported a dramatic enhancement of MDMA-induced brain hyperthermia during social interaction and in a warm environment $\left(29^{\circ} \mathrm{C}\right)$, and established the critical role of peripheral vasoconstriction in mediating these effects (Kiyatkin et al, 2014). Here, we tested whether similar hyperthermic effects would be observed in rats after exposure to the new 'bath-salts' drugs methylone and MDPV. We found that like MDMA, both drugs increased brain (NAc) temperatures within a physiological range $\left(\sim 2{ }^{\circ} \mathrm{C}\right)$ and induce a modest vasoconstriction when administered under standard laboratory conditions $\left(23^{\circ} \mathrm{C}\right.$, singly housed and quiet rest). Importantly, unlike MDMA, we found no evidence for strong potentiation of hyperthermic or vasoconstrictive effects of methylone and MDPV during social interaction or in warm ambient temperatures. Although brain hyperthermic effects of MDPV were slightly enhanced under these conditions, both hyperthermic and vasoconstrictive effects of methylone did not change significantly, and even slightly decreased when the drug was injected during social interaction and at warm ambient temperatures.

\section{Methylone and MDPV Effects Under Quiet Resting Conditions: Comparison with MDMA}

We administered methylone and MDPV to rats at doses (1-9 and $0.1-1 \mathrm{mg} / \mathrm{kg}$, respectively) that match the wide 
Quiet Rest, $23^{\circ} \mathrm{C}$

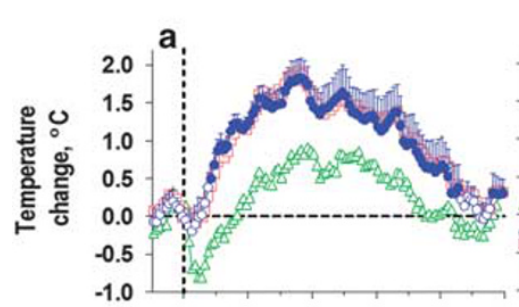

Social Interaction $29^{\circ} \mathrm{C}$
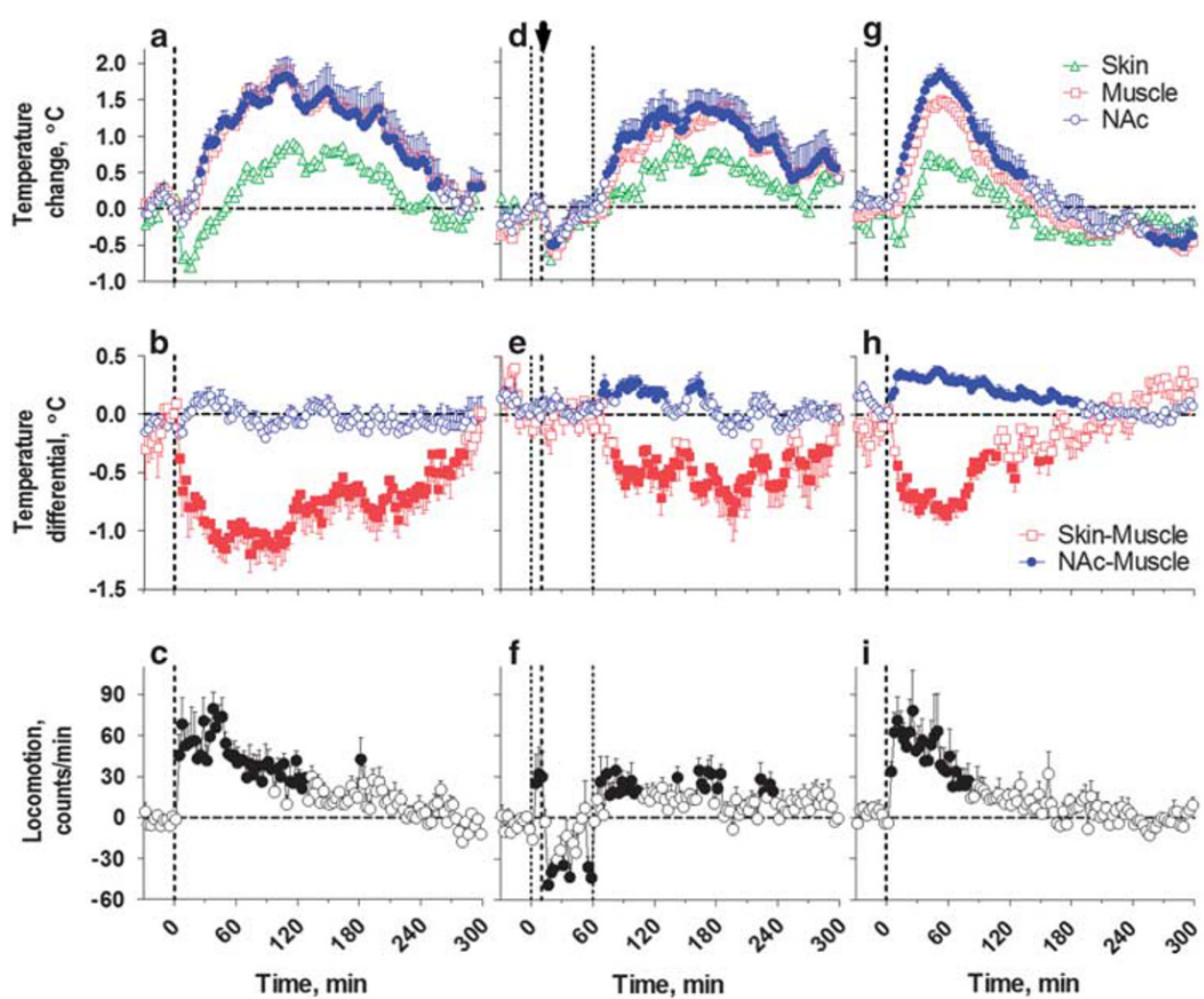

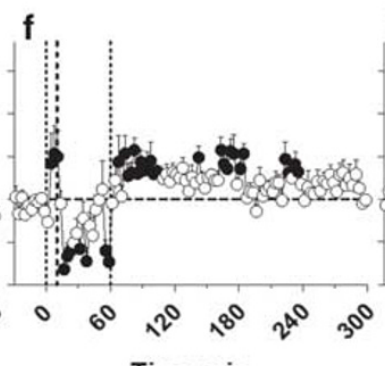

Time, $\min$

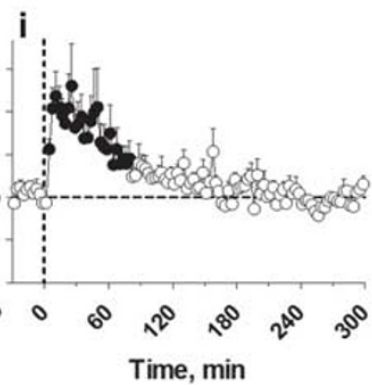

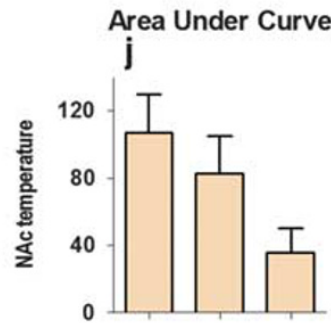
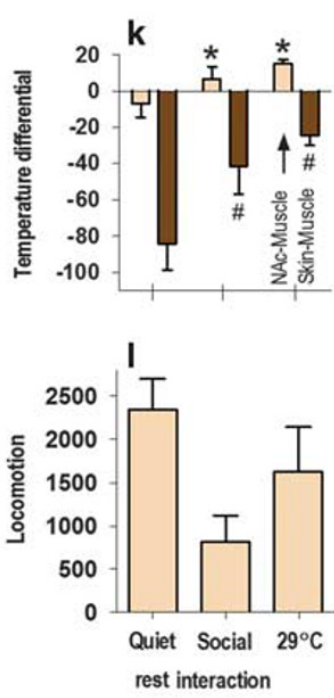

Figure 4 Net effects of methylone (drug minus saline) in rats under quiet resting conditions (a-c), during social interaction ( $d-f$ ), and at $29{ }^{\circ} \mathrm{C}$ ambient temperatures $(\mathrm{g}-\mathrm{i})$. Top graphs show relative temperature changes, middle graphs show temperature differentials, and bottom graphs show changes in locomotor activity. Filled symbols show values significantly different from baseline (at least $P<0.05$ ). Right panel $(j-l)$ show mean changes of individual parameters for $5 \mathrm{~h}$ post injection (area under the curve). The effect of experimental conditions was significant for NAc-Muscle and Skin-Muscle differentials $\left(F_{2,17}=6.7\right.$ and 4.9, respectively; $\left.P<0.05\right)$, and approached significance for NAc temperature and locomotion $\left(F_{2,17}=2.9\right.$ and $3.2 ; P=0.08$ and 0.07 , respectively). Asterisks and hash marks in ( $k$ ) show significant between-condition differences for NAc-Muscle and Skin-Muscle differentials $(P<0.05$; Fisher's PLSD test).

range used recreationally by humans. Both of these drugs are usually self-administered orally, with typical active doses of 100-300 mg for methylone and 5-20 mg for MDPV (see www.erowid.org for human self-reports). However, these drugs are sometimes taken at much higher doses (up to 1000 and $200 \mathrm{mg}$, respectively) and via other administration routes. Under standard laboratory conditions, methylone and MDPV induced relatively modest increases in NAc and muscle temperatures, which even at the highest doses were similar in magnitude $\left(\sim 1.8^{\circ} \mathrm{C}\right)$ to those seen during social interaction $\left(\sim 2.0^{\circ} \mathrm{C}\right)$. However, these drug effects were more prolonged than that of social interaction. In contrast to MDMA, a drug that strongly increases NAcMuscle differentials, suggesting intense intra-brain heat production (Kiyatkin et al, 2014), methylone and MDPV had minimal effects on this parameter.

Similar to MDMA, both drugs dose-dependently decreased Skin-Muscle differentials, indicating cutaneous vasoconstriction as a primary effector mechanism responsible for their hyperthermic effects. However, the vasoconstrictive effects of methylone and MDPV were weaker and significantly shorter in duration than those of MDMA. Consistent with previous studies in rats (Baumann et al, 2012; Aarde et al, 2013), MDPV was at least 10-fold more potent than methylone at inducing hyperthermia, vasocon- striction, and motor activation. These differences in drug potency are likely due to the greater affinity of MDPV for monoamine transporters, the primary targets of stimulant drug action in the brain (Baumann et al, 2013b). Specifically, MDPV is a pure uptake inhibitor, causing potent blockade of dopamine and noradrenaline transporters $\left(\mathrm{IC}_{50}=4.1\right.$ and $26 \mathrm{nM}$, respectively). In contrast, methylone is a non-selective transporter substrate that releases dopamine, noradrenaline, and serotonin from brain synaptosomes with EC50s ranging from 100 to $200 \mathrm{nM}$.

\section{Modulation of the Hyperthermic Effects of Methylone and MDPV by Social Interaction and Warm Ambient Temperature}

The brain and body hyperthermic effects of MDMA are strongly enhanced during social interaction and at moderately warm ambient temperatures (Brown and Kiyatkin, 2004; Kiyatkin et al, 2014). In the latter case, most rats develop fatal brain hyperthermia $\left(>41^{\circ} \mathrm{C}\right)$. Surprisingly, this type of potentiation was minimal with MDPV and not evident with methylone. Pathological hyperthermia or any other adverse effects were not observed with either drug used under our experimental conditions in rats. 
Quiet Rest, $23^{\circ} \mathrm{C}$
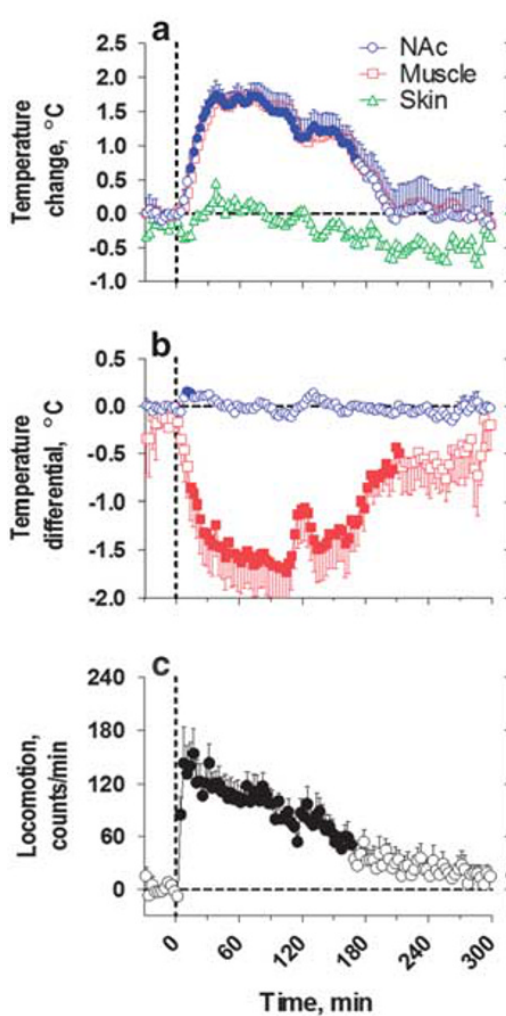

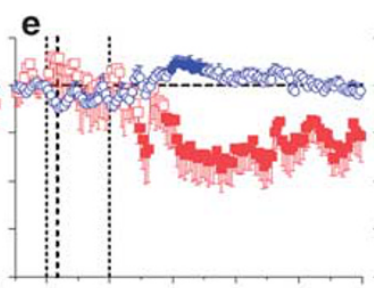

Social Interaction
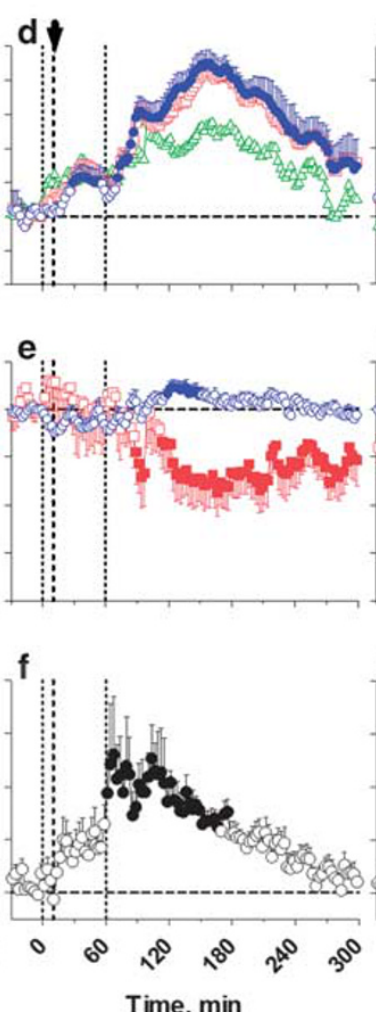

$29^{\circ} \mathrm{C}$
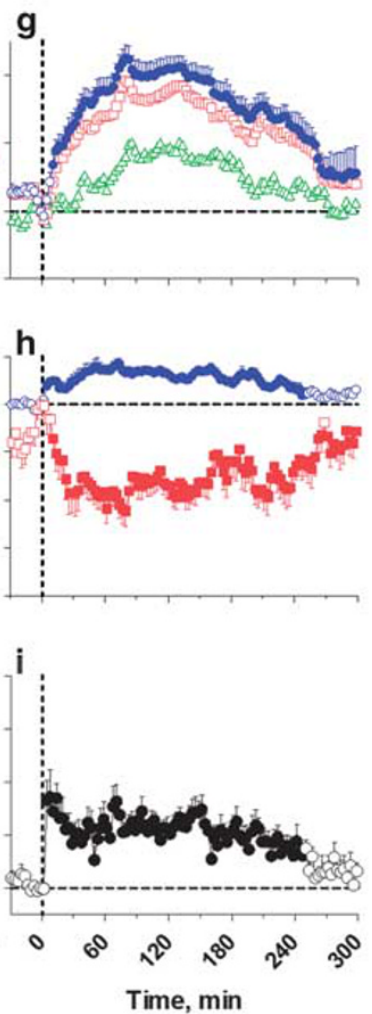

Area Under Curve
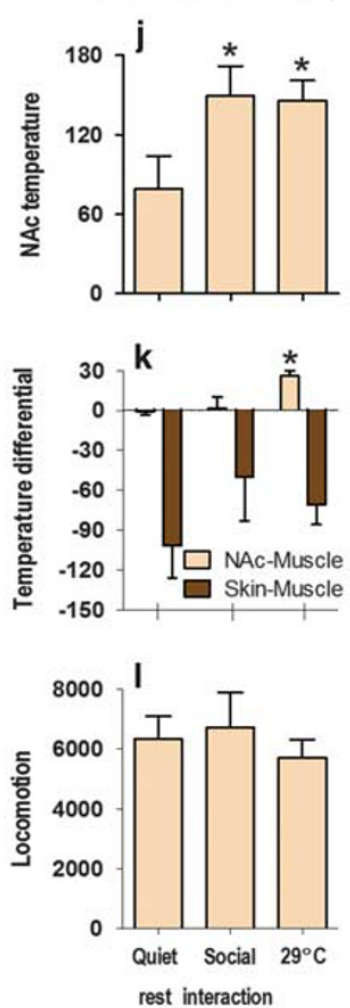

Figure 5 Net effects of MDPV (drug minus saline) in rats under quiet resting conditions $\left(\mathrm{a}-\mathrm{c}\right.$ ), during social interaction ( $\mathrm{d}-\mathrm{f}$ ), and at $29^{\circ} \mathrm{C}$ ambient temperatures $(\mathrm{g}-\mathrm{i})$. Top graphs show relative temperature changes, middle graphs show temperature differentials, and bottom graphs show changes in locomotor activity. Filled symbols show values significantly different from baseline $(P<0.05)$. Right panel $(j-l)$ show mean changes in individual parameters for $5 \mathrm{~h}$ post injection (area under curve). The effect of experimental conditions was significant for NAc temperature and NAc-Muscle differentials $\left(F_{2,22}=3.5\right.$ and 7.3, respectively; $P<0.05)$ but not for Skin-Muscle differentials and locomotion. Asterisks show significant differences vs quiet resting conditions $(P<0.05$; Fisher's PLSD test).

We used social interaction between two rats to model physiological activation, a typical condition associated with human drug use. This procedure resulted in moderate motor activation and $\mathrm{a} \sim 2{ }^{\circ} \mathrm{C}$ rise in brain temperature. It also induced a rapid, transient rise in NAc-Muscle differentials and an equally rapid but more prolonged drop in Skin-Muscle differentials, suggesting two factors-intra-brain heat production and cutaneous vasoconstriction-as critical contributors to this physiological hyperthermia. In contrast to the monophasic NAc temperature increase induced by methylone under quiet resting conditions, this increase was delayed, more prolonged, and preceded by a small but significant decrease $\left(\sim 0.6^{\circ} \mathrm{C}\right)$ within $20-30$ min post injection when the drug was injected during social interaction. Under these conditions, the decrease in Skin-Muscle differentials produced by methylone was delayed and smaller, suggesting weaker cutaneous vasoconstriction. Although atypical for MDMA and methamphetamine (Brown et al, 2003), this lack of potentiation suggests that methylone and social interaction share common effector mechanisms (eg, sympathetic activation) to induce brain hyperthermia. When these mechanisms are naturally activated during social interaction (ie, when rats are hyperactive, brain metabolic activity is increased and cutaneous vessels are physiologically constricted), the effects of the drug per se become weaker while the overall hyperthermic response does not change.
We found a similar lack of potentiation for hyperthermic effects of methylone when the drug was injected at warm ambient temperatures. Despite a slight increase in basal NAc and muscle temperatures, and warmer skin surfaces (ie, vasodilatation to enhance heat dissipation), the mean NAc temperature increase induced by methylone at $29^{\circ} \mathrm{C}$ did not change and the net effects of the drug were similar in magnitude but shorter in duration than those seen at $22-23^{\circ} \mathrm{C}$. Surprisingly, despite background vasodilation typical of warm ambient temperatures, the vasoconstrictive effects of methylone also weakened compared with standard laboratory conditions. Although the exact mechanisms underlying this dampening of drug effects remain unclear, it may be related to more rapid metabolism of methylone that may occur at higher temperatures.

The hyperthermic effects of MDPV also showed modest changes during social interaction and at warm ambient temperatures. Similar to methylone, the immediate effects of MDPV on brain and muscle temperatures during social interaction were smaller than after saline injections (see Figure $4 \mathrm{~d}$ ), but both temperatures decreased to baselines slower than in the saline-injected group. The net effects of MDPV on brain temperature were about the same as those in quiet resting conditions, but they were delayed and prolonged during social interaction, resulting in weak but significant increase in the area under the curve. We 

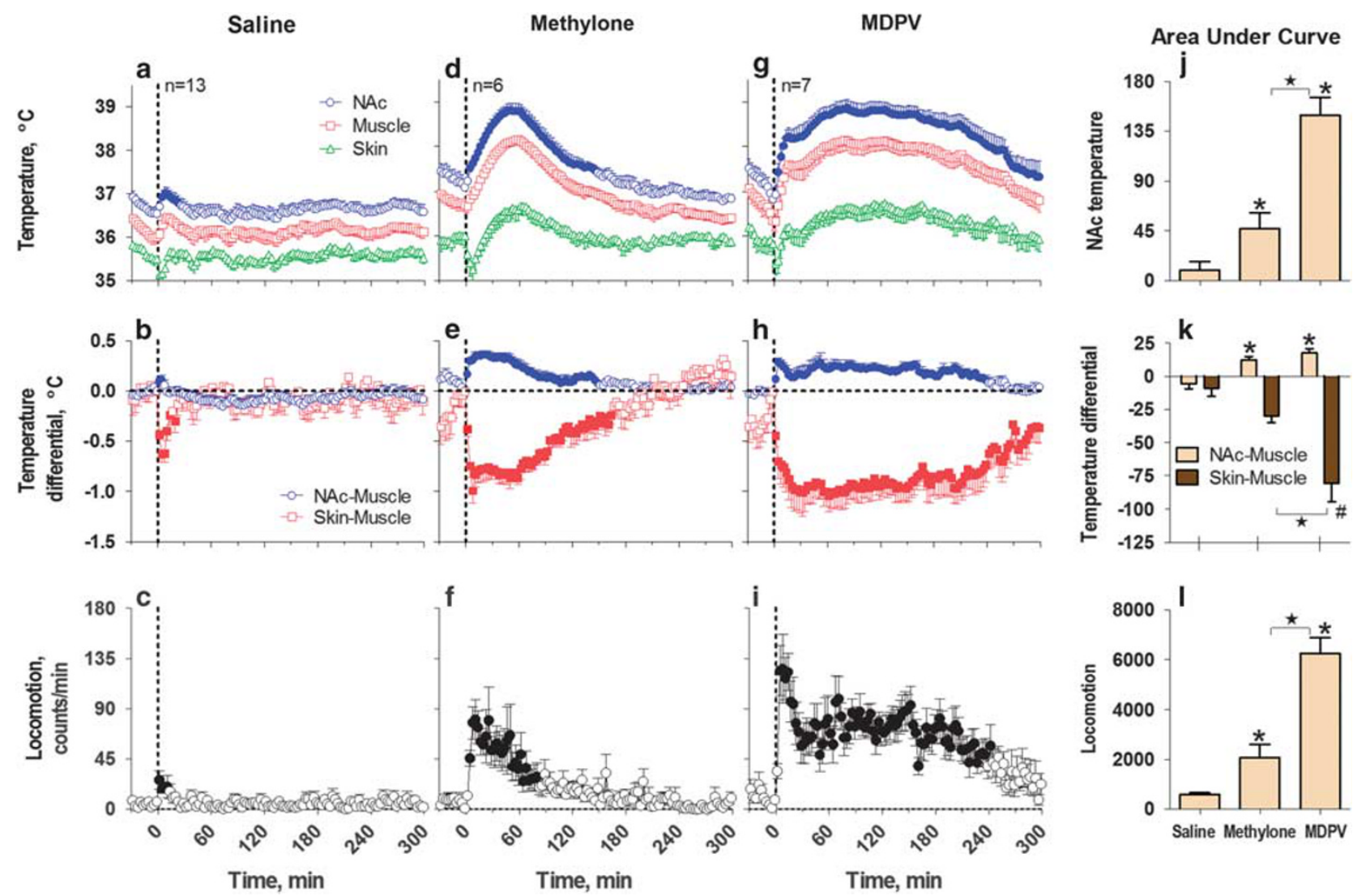

Figure 6 Changes in temperature and locomotion induced by injections of saline $(a-c)$, methylone ( $d-f)$, and MDPV ( $g-i)$ in rats under quiet resting conditions at $29^{\circ} \mathrm{C}$. Top graphs show absolute temperature changes, middle graphs show temperature differentials, and bottom graphs show changes in locomotor activity. $n=$ number of averaged responses per group. Values significantly different from baseline $(P<0.05)$ are shown as filled symbols. Right panel $(j-1)$ shows mean \pm SEM values of temperature and locomotor responses assessed by the area under the curve for $5 \mathrm{~h}$ post injection. The effect of drug treatment was significant for NAc temperature, NAc-Muscle and Skin-Muscle differentials, and locomotion $\left(F_{2,25}=39.5,10.8,17.6\right.$ and $64.3 ; P<0.05$, respectively; $P<0.05)$. Asterisks show significant differences vs saline and stars show significant between-drug differences $(P<0.05 ;$ Fisher's $P L S D$ test).

also found a similarly weak potentiation of hyperthermic effects of MDPV when the drug was injected at $29^{\circ} \mathrm{C}$. In this case, increases in NAc temperature did not change in magnitude but became more prolonged. Although the druginduced decreases in Skin-Muscle differential became slightly weaker, the NAc-Muscle differential strongly increased, suggesting enhanced intra-cerebral heat production as an additional factor determining prolonged brain temperature increases induced by MDPV at warm ambient temperatures.

\section{Conclusions and Translational Relevance}

We found that brain and body hyperthermic effects of methylone and MDPV in rats are modest in magnitude $\left(\sim 2{ }^{\circ} \mathrm{C}\right)$ even at relatively high drug doses that exceed the range of 'typical' human recreational consumption. These effects are modulated by social interaction and warm environments, but the pattern of modulation differs markedly from that produced by MDMA and methamphetamine (Brown et al, 2003; Kiyatkin, 2013; Kiyatkin et al, 2014). Although MDMA and methylone have similar potency as monoamine releasing agents (Baumann et al, 2012; Eshleman et al, 2013; Simmler et al, 2013) and both drugs induce moderate hyperthermic effects under quiet resting conditions, the MDMA-induced hyperthermia is greatly enhanced during social interaction and in warm environments (synergistic or supra-additive interaction) (Kiyatkin et al, 2014), whereas the effects of methylone do not show additive interaction. Similar to methamphetamine, MDPV displays potent activity at dopamine and norepinephrine transporters (Baumann et al, 2012, 2013b), but methamphetamine is a transporter-releasing agent whereas MDPV is a transporter blocker. Although both drugs induce robust locomotor activation, the hyperthermic effects of MDPV are much weaker than those of methamphetamine and they are less affected by activity state and environmental conditions that mimic human drug use. However, MDPV did show a weak additive interaction when injected during social interaction and at $29^{\circ} \mathrm{C}$, but these effects were much weaker than those seen with MDMA and methamphetamine.

It is important to note that our present results and previous findings in rodent models (Baumann et al, 2012; Aarde et al, 2013; Fantegrossi et al, 2013) do not necessarily imply that these 'bath-salt' drugs cannot induce serious health complications in humans (eg, see Introduction). Although animal experiments are essential to examine the effects of drugs under controlled conditions and to explore underlying mechanisms, significant issues such as between- 
species dose equivalency remain in translating work done in rodent models to humans. Additionally, animal experiments do not mimic all aspects of recreational drug use. In humans, 'bath-salt' drugs are often taken repeatedly by individuals with extensive poly-drug experience, during high activity states (eg, sexual activity, dancing), under environmental conditions that prevent proper heat dissipation (eg, high temperature and humidity, specific clothing), and frequently in combination with other psychoactive drugs. Although each of these factors alone has a limited potential to influence the effects of 'bath-salts' drugs, their combination can drive drug-induced physiological changes to their extremes, resulting in adverse health complications.

\section{FUNDING AND DISCLOSURE}

The authors declare no conflict of interest.

\section{ACKNOWLEDGEMENTS}

This study is supported by the National Institute on Drug Abuse, Intramural Research Program, NIH. The Authors declare no any financial interests in relation to the work described.

\section{REFERENCES}

Aarde SM, Huang PK, Creehan KM, Dickerson TJ, Taffe MA (2013). The novel recreational drug 3,4-methylenedioxypyrovalerone (MDPV) is a potent psychomotor stimulant: self-administration and locomotor activity in rats. Neuropharmacology 71: 130-140.

Badiani A, Belin D, Epstein D, Calu D, Shaham Y (2011). Opiate versus psychostimulant addiction: the differences do matter. Nat Rev Neurosci 12: 685-700.

Baumann MH, Ayestas MA Jr, Partilla JS, Sink JR, Shulgin AT, Daley $\mathrm{PF}$ et al (2012). The designer methcathinone analogs, mephedrone and methylone, are substrates for monoamine transporters in brain tissue. Neuropsychopharmacology 37: 1192-1203.

Baumann MH, Partilla JS, Lehner KR (2013a). Psychoactive "bath salts": not so soothing. Eur J Pharmacol 698: 1-5.

Baumann MH, Partilla JS, Lehner KR, Thorndike EB, Hoffman AF, Holy $\mathrm{M}$ et al (2013b). Powerful cocaine-like actions of 3,4methylenedioxypyrovalerone (MDPV), a principal constituent of psychoactive 'bath salts' products. Neuropsychopharmacology 38: $552-562$.

Borek HA, Holstege CP (2012). Hyperthermia and multiorgan failure after abuse of "bath salts" containing 3,4-methylenedioxypyrovalerone. Ann Emerg Med 60: 103-105.

Brown PL, Kiyatkin EA (2004). Brain hyperthermia induced by MDMA (ecstasy): modulation by environmental conditions. Eur J Neurosci 20: 51-58.

Brown PL, Wise RA, Kiyatkin EA (2003). Brain hyperthermia is induced by methamphetamine and exacerbated by social interaction. J Neurosci 23: 3924-3929.

Cameron KN, Kolanos R, Solis E Jr, Glennon RA, De Felice LJ (2013). Bath salts components mephedrone and methylenedioxypyrovalerone (MDPV) act synergistically at the human dopamine transporter. Br J Pharmacol 168: 1750-1757.

DEA (2011). Schedules of controlled substances: temporary placement of three synthetic cathinones in Schedule 1. In: Administration DE (ed) Fed Regist 76 Vol Final Orderpp 65371-65375.
Eshleman AJ, Wolfrum KM, Hatfield MG, Johnson RA, Murphy KV, Janowsky A (2013). Substituted methcathinones differ in transporter and receptor interactions. Biochem Pharmacol 85: 1803-1815.

Fantegrossi WE, Gannon BM, Zimmerman SM, Rice KC (2013). In vivo effects of abused 'bath salt' constituent 3,4-methylenedioxypyrovalerone (MDPV) in mice: drug discrimination, thermoregulation, and locomotor activity. Neuropsychopharmacology 38: $563-573$.

German CL, Fleckenstein AE, Hanson GR (2014). Bath salts and synthetic cathinones: an emerging designer drug phenomenon. Life Sci 97: 2-8.

Kesha K, Boggs CL, Ripple MG, Allan CH, Levine B, Jufer-Phipps R et al (2013). Methylenedioxypyrovalerone ("bath salts"), related death: case report and review of the literature. J Forensic Sci 58: 1654-1659.

Kiyatkin EA (2010). Brain temperature homeostasis: physiological fluctuations and pathological shifts. Front Biosci 15: 73-92.

Kiyatkin EA (2013). The hidden side of drug action: brain temperature changes induced by neuroactive drugs. Psychopharmacology (Berl) 225: 765-780.

Kiyatkin EA, Brown PL (2004). Modulation of physiological brain hyperthermia by environmental temperature and impaired blood outflow in rats. Physiol Behav 83: 467-474.

Kiyatkin EA, Kim AH, Wakabayashi KT, Baumann MH, Shaham Y (2014). Critical role of peripheral vasoconstriction in fatal brain hypewrthermia induced by MDMA (Ecstasy) under conditions that mimic human drug use. J Neurosci 34: 7754-7762.

Merluzzi AP, Hurwitz ZE, Briscione MA, Cobuzzi JL, Wetzell B, Rice KC et al (2013). Age-dependent MDPV-induced taste aversions and thermoregulation in adolescent and adult rats. Dev Psychobiol 56: 943-954.

Mogenson GJ, Jones DL, Yim CY (1980). From motivation to action: functional interface between the limbic system and the motor system. Prog Neurobiol 14: 69-97.

Murray BL, Murphy CM, Beuhler MC (2012). Death following recreational use of designer drug "bath salts" containing 3,4Methylenedioxypyrovalerone (MDPV). J Med Toxicol 8: 69-75.

Pearson JM, Hargraves TL, Hair LS, Massucci CJ, Frazee CC 3rd, Garg U et al (2012). Three fatal intoxications due to methylone. J Anal Toxicol 36: 444-451.

Prosser JM, Nelson LS (2012). The toxicology of bath salts: a review of synthetic cathinones. J Med Toxicol 8: 33-42.

Romanovsky AA, Ivanov AI, Shimansky YP (2002). Selected contribution: ambient temperature for experiments in rats: a new method for determining the zone of thermal neutrality. J Appl Physiol 92: 2667-2679.

Ross EA, Reisfield GM, Watson MC, Chronister CW, Goldberger BA (2012). Psychoactive "bath salts" intoxication with methylenedioxypyrovalerone. Am J Med 125: 854-858.

Simmler LD, Buser TA, Donzelli M, Schramm Y, Dieu LH, Huwyler $J$ et al (2013). Pharmacological characterization of designer cathinones in vitro. Br J Pharmacol 168: 458-470.

Spiller HA, Ryan ML, Weston RG, Jansen J (2011). Clinical experience with and analytical confirmation of "bath salts" and "legal highs" (synthetic cathinones) in the United States. Clin Toxicol (Phila) 49: 499-505.

Watterson LR, Kufahl PR, Nemirovsky NE, Sewalia K, Grabenauer $\mathrm{M}$, Thomas BF et al (2014). Potent rewarding and reinforcing effects of the synthetic cathinone 3,4-methylenedioxypyrovalerone (MDPV). Addict Biol 19: 165-174.

Wise RA (1989). The brain and reward. In: Liebman JMKooper SJ (eds) The neuropharmacological basis of reward. Oxford University Press: Oxford, pp 377-424. 